\title{
Ambulatory Care Nursing
}

National Cancer Institute

\section{Source}

National Cancer Institute. Ambulatory Care Nursing. NCI Thesaurus. Code C20866.

Nursing care provided in an ambulatory setting, such as a clinic or physician's office. 